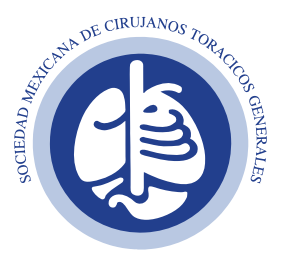

Vol. 1, Núm. 3

Septiembre-Diciembre 2020 pp 101-104

Palabras clave:

Resección traqueal,

estenosis traqueal,

COVID-19, cirugía de tórax.

\section{Keywords:}

Tracheal resection, tracheal stenosis, COVID-19,

thoracic surgery.

\title{
Resección traqueal con anastomosis término- terminal como tratamiento definitivo de estenosis traqueal en paciente infectado por COVID-19
}

\author{
Tracheal resection with end to end anastomosis as definitive \\ treatment of tracheal stenosis in a patient infected by COVID-19
}

Miguel Martínez-Arias, * Ulises Loyola-García, ${ }^{\neq}$

Armando Otero-Pérez, ${ }^{\S}$ Emmanuel Escobedo-Sánchez ${ }^{\S}$

\begin{abstract}
RESUMEN
Un porcentaje de los pacientes con infección por COVID-19 ha requerido manejo avanzado de la vía aérea, con necesidad de intubación orotraqueal, y la gran mayoría durante un período prolongado. Esta condición, sumada a otros factores de riesgo como diabetes, hipertensión, uso de esteroides, obesidad, entre otros, aumenta el riesgo de estenosis traqueal luego de la recuperación del paciente. Por lo que es esperado que la prevalencia de dicha complicación aumente en esta época. El manejo actual de la estenosis traqueal ha demostrado ser segura. Ante esta nueva enfermedad, hace falta conocer la evolución de los pacientes con complicaciones como la estenosis traqueal y saber si la propia infección por SARS-CoV-2 juega un papel determinante en la formación de la estenosis. Es importante tener en mente esta complicación de la intubación prolongada, para detectar de manera oportuna y dar el manejo adecuado. Se presenta la primera resección y anastomosis término-terminal en la era pos-COVID para tratar definitivamente la estenosis provocada por intubación.
\end{abstract}

\section{ABSTRACT}

A percentage of patients with COVID-19 infection have required advanced airway management, requiring orotracheal intubation, and the vast majority for a prolonged period. This condition, added to other risk factors such as diabetes, hypertension, steroid use, obesity, among others, increase the risk of tracheal stenosis after the patient's recovery. Therefore, the prevalence of this complication is expected to increase at this time. The current management of tracheal stenosis has proven to be safe. Faced with this new disease, it is necessary to know the evolution of patients with complications such as tracheal stenosis and to know if the SARS-CoV-2 infection itself plays a determining role in the formation of the stenosis. It is important to keep in mind this complication of prolonged intubation, to detect it in a timely manner and give proper management. The first resection and end-to-end anastomosis is presented in the post-COVID era to definitively treat stenosis caused by intubation.

\section{INTRODUCCIÓN}

Es bien conocida la relevancia que ha tomado la intubación orotraqueal para el apoyo ventilatorio mecánico en pacientes con neumonía por SARS-CoV-2, causante de la presente pandemia. ${ }^{1}$ Se estima que alrededor del 1\% de los casos con intubación

Citar como: Martínez-Arias M, Loyola-García U, Otero-Pérez A, Escobedo-Sánchez E. Resección traqueal con anastomosis término-terminal como tratamiento definitivo de estenosis traqueal en paciente infectado por COVID-19. Rev Mex Cir Torac Gen. 2020; 1(3): 101-104. https://dx.doi.org/10.35366/101479 


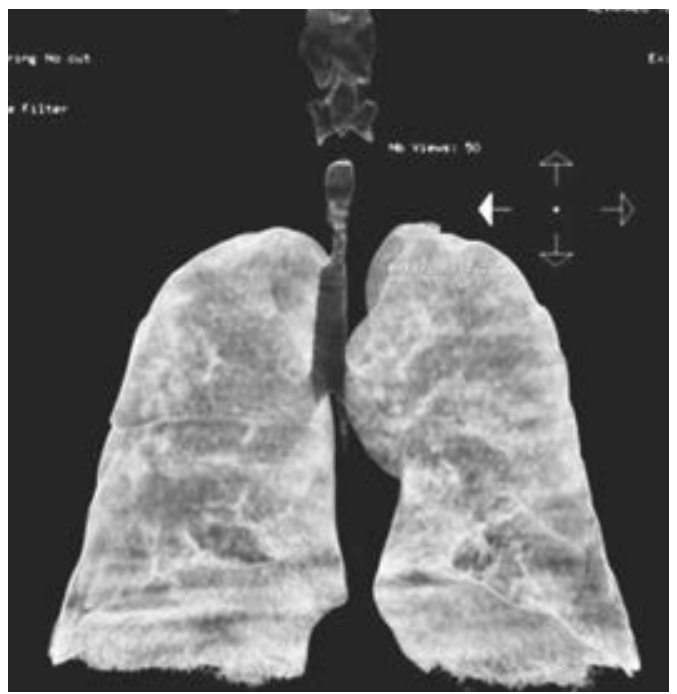

Figura 1: Reconstrucción 3D traqueal y pulmonar.

orotraqueal prolongada (21 o más días de intubación) pueden desarrollar estenosis traqueal. Considerando que hasta el 1\% con COVID-19 podrían requerir ser intubados, es esperado que dicha complicación tenga una prevalencia importante entre los pacientes recuperados. ${ }^{2}$

En la actualidad, sólo algunos casos aislados han sido reportados, ${ }^{3}$ hace falta información para dilucidar diferencias de estenosis posintubación entre pacientes COVID-19 y no COVID-19. Las descripciones histológicas de las estenosis mencionan pérdida de células ciliadas y proliferación con hiperplasia de células basales.

\section{PRESENTACIÓN DEL CASO}

Se presenta el caso de un hombre de 61 años de edad, con antecedente de diabetes mellitus tipo 2, con 10 años de diagnóstico, quien fue admitido en nuestro hospital (Estado de México, México) el 27 de abril del 2020, con síndrome respiratorio agudo severo, por neumonía atípica causada por SARSCoV-2, corroborado por prueba PCR (+) requirió manejo avanzado de la vía aérea, intubado el mismo 27 de abril. Durante su estancia, recibió manejo con hidroxicloroquina, azitromicina, oseltamivir, omeprazol, paracetamol y enoxaparina. Además, cursó con neumonía asociada al ventilador, por lo que cumplió un esquema con meropenem. El día 19 de mayo fue extubado de manera exitosa y egresado por mejoría el 25 de mayo completamente asintomático y con requerimiento de oxígeno suplementario por puntas nasales a dosis bajas.

A dos semanas de su egreso y tres de haber sido extubado, presenta estridor laríngeo vespertino, que fue progresando hasta hacerse continuo y asociarse a disnea y cambios de voz. Por tal motivo, se presenta nuevamente en la sala de urgencias, donde se realiza una tomografía con broncoscopia virtual (Figuras 1 y 2), con la que se corrobora el diagnóstico de estenosis traqueal.

El día 6 de julio con una nueva PCR la cual resultó negativa, a 70 días de prueba PCR previa, se realiza una broncoscopia flexible, observando estenosis del $70 \%$ de la luz traqueal del segundo, tercer y cuarto anillos traqueales, con 10 anillos distales libres de estenosis, se realiza dilatación, dejando luz del 90\%. El sujeto es egresado por mejoría; sin embargo, dos semanas después se presenta nuevamente con los mismos síntomas, siempre manteniendo saturación del $92 \%$ con oxígeno al $21 \%$. Se decide realizar nueva broncoscopia, esta vez encontrando estenosis de $80 \%$.

Por los hallazgos en broncoscopia y el corto tiempo de recidiva, se decide otorgar tratamiento quirúrgico, por lo que el 20 de julio se realiza traqueoplastía, donde se resecaron los primeros cuatro anillos traqueales,

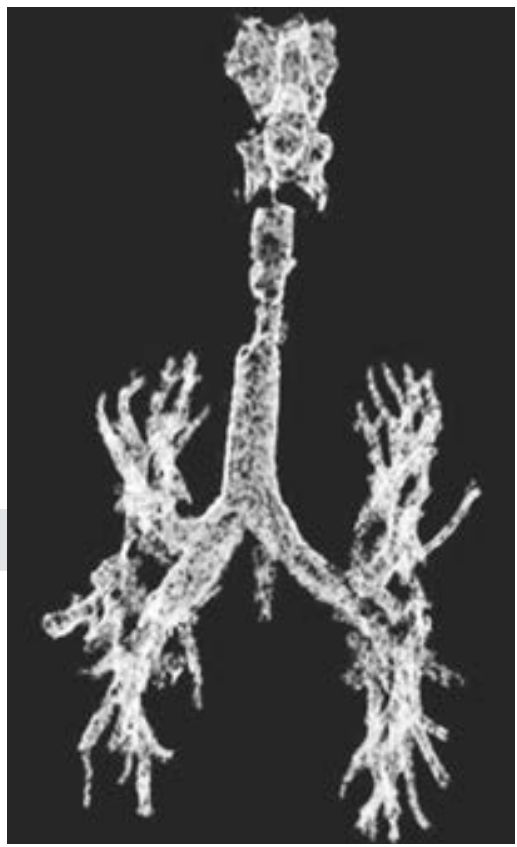

Figura 2:

Reconstrucción 3D traqueal. 


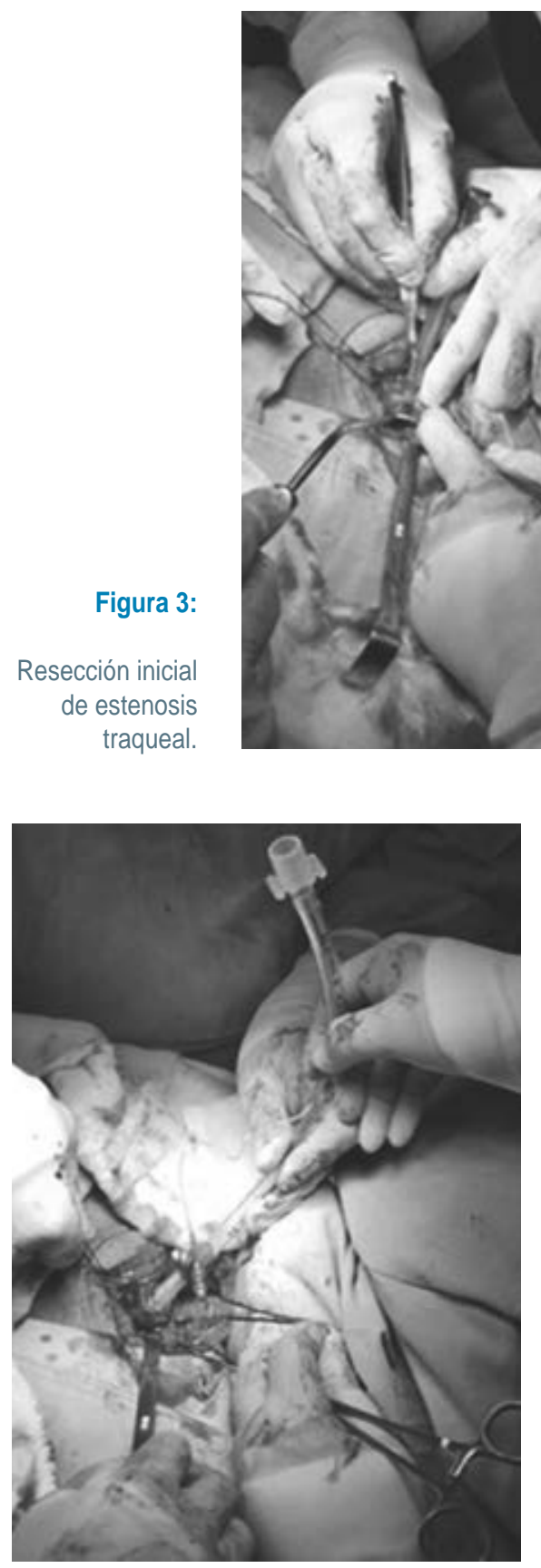

Figura 4:

Manejo de vía aérea intracampo.

afectados por una estenosis concéntrica de más del 80\% del diámetro de la tráquea en su sitio más estrecho, con cricotraqueo anastomosis término-terminal (Figuras 2 a 7).

Se colocó punto de fijación del mentón a la piel del tórax anterior a la altura de la unión del manubrio y el cuerpo del esternón, asimismo, se indicó flexión cervical estricta al paciente, el cual evolucionó de manera

favorable y una semana después del procedimiento quirúrgico fue egresado del hospital completamente asintomático.

Se ha dado seguimiento por cuatro semanas, hasta el momento no ha presentado complicaciones posquirúrgicas y tampoco datos de estenosis traqueal. Por el momento se encuentra pendiente la realización de broncoscopia posquirúrgica.

Figura 5:

Anastomosis

posterior

traqueal.
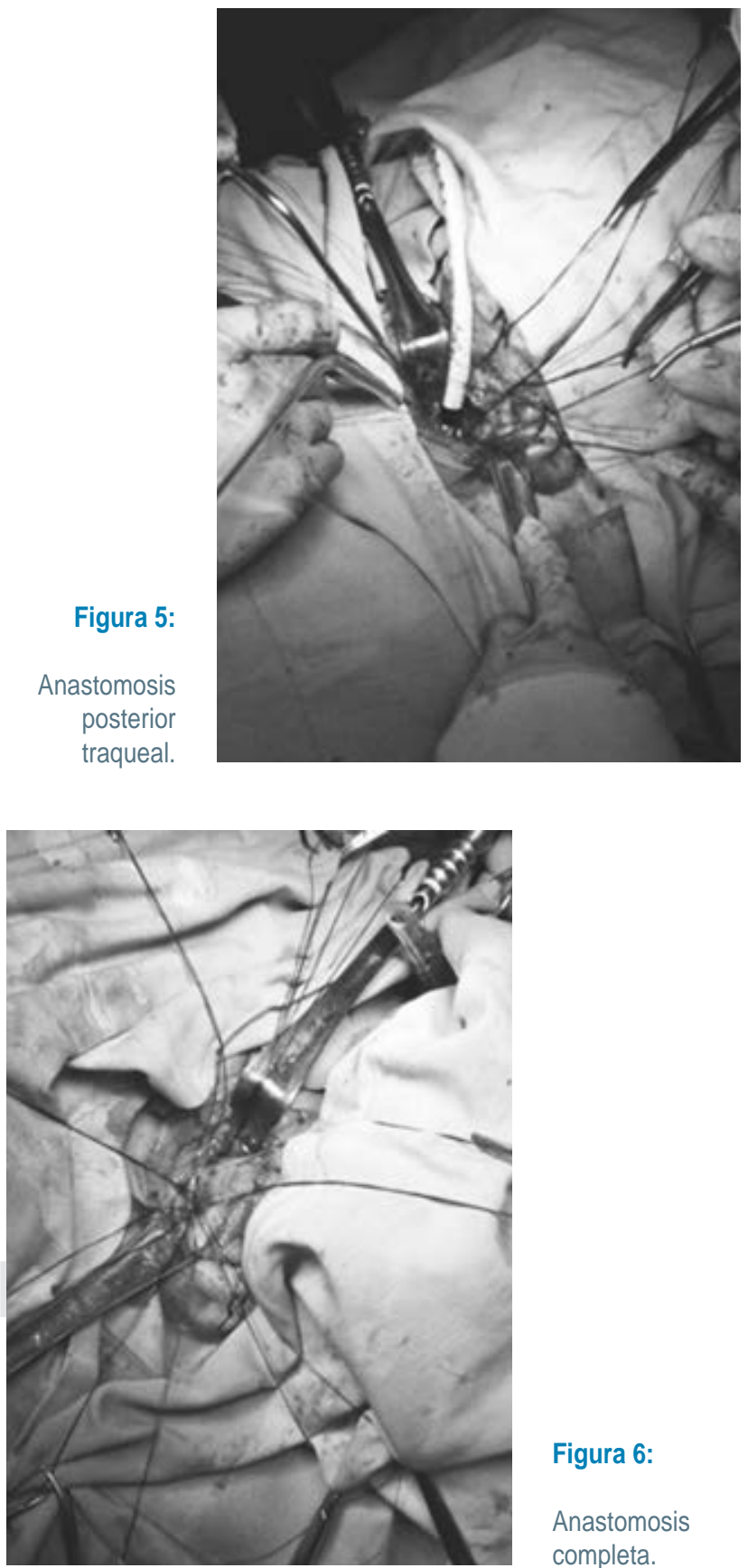

Figura 6:

Anastomosis completa. 


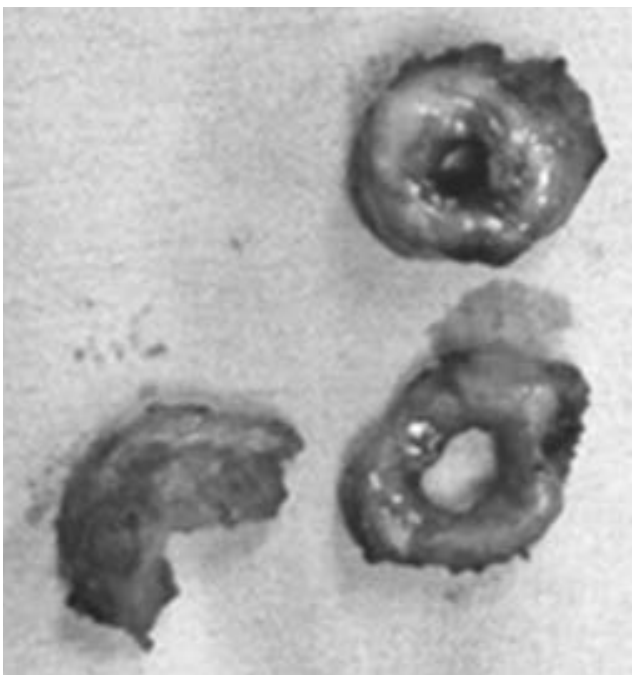

Figura 7: Anillos traqueales.

\section{DISCUSIÓN}

Presentamos un caso con intubación prolongada (22 días), que después de tres semanas de su extubación presentó datos de estenosis traqueal, se dio manejo inicial con dilatación con globo por medio de broncoscopia y posteriormente con cánulas orotraqueales; sin embargo, el paciente presentó aumentó de la estrechez del diámetro de la tráquea, por lo que se tuvo que buscar el manejo definitivo.

A pesar de que se conocen los mecanismos implicados y los factores de riesgo asociados, como la diabetes, hipertensión, obesidad, algunas enfermedades reumatológicas, el uso de esteroides, etcétera, no está claro hasta el momento cuál es la relevancia de la infección por COVID-19 y si ésta juega un papel determinante en la estenosis traqueal. El reporte final de patología de este paciente se describió con presencia de cartílago, glándulas mucosas rodeadas de fibrosis, vasos de neoformación y linfocitos mononucleares. Hoy en día, sabemos que la infección por SARS-CoV-2 desencadena una tormenta inflamatoria de citoquinas, que dañan múltiples órganos y que pudiera estar implicado en la formación de fibrosis y tejido de granulación en la tráquea en los sitios de estenosis.

\section{CONCLUSIONES}

La estenosis traqueal posintubación con o sin traqueostomía debe considerarse en pacientes recuperados de COVID-19 severo, ya que además de la intubación prolongada, cuentan con otros factores de riesgo para el desarrollo de la estenosis, como la microangiopatía vascular secundaria a enfermedades crónicas degenerativas, el uso de esteroides, la pronación, etcétera. En este caso, no encontramos alguna característica distintiva del tejido con respecto a las estenosis de pacientes sin antecedente de COVID. Un seguimiento cuidadoso de estos casos nos permitirá detectar estenosis traqueales y darles manejo de manera temprana.

\section{REFERENCIAS}

1. Meng L, Qiu H, Wan L, Ai Y, Xue Z, Guo Q et al. Intubation and ventilation amid the COVID-19 outbreak: Wuhan's experience. Anesthesiology. 2020; 132, 1317-1332: 1-16.

2. Blot F, Similowski T, Trouillet JL, Chardon P, Korach JM, Costa MA et al. Early tracheotomy versus prolonged endotracheal intubation in unselected severely ill ICU patients. Intensive Care Med. 2008; 34(10): 1779-1787.

3. Mattioli F, Fermi M, Ghirelli M, Molteni G, Sgarbi N, Bertellini E et al. Tracheostomy in the COVID-19 pandemic. Eur Arch Oto-RhinoLaryngology. 2020; (0123456789): 3-5. Available from: https://doi. org/10.1007/s00405-020-05982-0. 